\title{
O BRASIL E A EXECUÇÃO PECUNIÁRIA DA CORTE INTERAMERICANA DE DIREITOS HUMANOS
}

\author{
BRAZIL AND THE PECUNIARY EXECUTION OF THE INTER- \\ AMERICAN COURT OF HUMAN RIGHTS
}

\author{
Dimas Pereira Duarte Junior ${ }^{1}$ \\ Diogo de Calasans Melo Andrade ${ }^{2}$ \\ Flávio Prado Fonseca ${ }^{3}$
}

\section{RESUMO}

Desde a adesão e ratificação, por parte do Brasil, da Carta da Organização dos Estados Americanos, as decisões proferidas pela Corte Interamericana de Direitos Humanos passaram a ocupar um lugar de destaque no âmbito jurídico brasileiro. Despertou-se, assim, o interesse da comunidade jurídica em, além de analisar as decisões em si, pormenorizar os seus devidos cumprimentos por parte do país signatário. No presente estudo, busca-se verificar a execução pecuniária das decisões da Corte, observando-se de que forma o Brasil cumpre estas decisões que determinam uma obrigação em forma de pecúnia e onde se processa este cumprimento de sentença. Desta forma, não se abrange no presente artigo as decisões que impõem uma obrigação de fazer e não fazer. Assim, inicialmente, serão identificadas as decisões em que o Brasil ocupa o polo passivo para, só depois, observar as que determinam uma obrigação pecuniária. Após destacadas, observa-se de que forma a execução ocorre e qual órgão é o responsável por seu cumprimento. Com isso, busca-se analisar se existe alguma lei federal que trate a respeito do tema ou, se o Congresso Nacional já sinalizou a respeito com algum projeto de lei em andamento.

\section{PALAVRAS-CHAVE:}

Brasil; Corte Interamericana; Direitos Humanos; Execução; Sentença.

\footnotetext{
${ }^{1}$ Doutor em Ciências Sociais: Relações Internacionais pela PUC/SP. Professor de Direito Internacional e Direitos Humanos. Pesquisador do Programa de Pós-Graduação em Direitos Humanos (ME/DO) da Universidade Tiradentes - UNIT/SE. E-mail: dimas.duartejr@ gmail.com

2 Doutor em Direito Político e Econômico pela Universidade Mackenzie. Mestre em Direito, na área de constitucionalização do direito pela UFS. Professor titular da graduação e do mestrado e doutorado em direitos humanos do PPGD-UNIT. Líder do grupo de pesquisa "Novas tecnologias e o impacto nos Direitos Humanos" do mestrado em direito Humanos da UNIT, advogado. E-mail: contato@diogocalasans.com

${ }^{3}$ Analista do Ministério Público de Sergipe. Mestrando em Direitos Humanos da Universidade Tiradentes - UNITSE. E-mail: flaviopfonseca@hotmail.com
} 


\begin{abstract}
As Brazil ratified and accepted the conditions in the Declaration of the Organization of American States, the decisions taken by the Inter-American Court of Human Rights have become an influence in the Brazilian legal context. In this sense, the legal community became more and more interested in the analysis of the decisions and the internal national instruments of compliance. The present study attempts to verify the pecuniary execution of the decisions taken by the Inter-American Court. Thus, it is focused on the ways Brazil complies and enforces these decisions concerning the determination of a pecuniary obligation. Initially, the process developed in this investigation identifies the decisions that bring Brazil as the passive pole, and then only the ones concerning a pecuniary obligation are selected for the following analysis. After that, it is observed how the execution takes place and what are the juridical norms that are responsible for the internal compliance. Therefore, this investigation seeks to contribute with an analysis of whether there is any federal law dealing with the matter of instruments for the compliance of pecuniary obligations, or if there is a bill that has been analyzed by the National Congress.
\end{abstract}

\title{
KEYWORDS:
}

Brazil; Inter-American Court; Human Rights; Execution; Sentence.

\section{INTRODUÇÃO}

O organismo regional mais antigo do mundo é a Organização dos Estados Americanos (OEA), que tem sua origem na Primeira Conferência Internacional Americana, realizada na cidade de Washington, D.C., de outubro de 1889 a abril de 1890. Como resultado, obteve-se a criação da União Internacional das Repúblicas Americanas, dando início, assim, ao que ficaria conhecido como "Sistema Americano" (OEA, 2020).

Desse modo, a OEA foi estabelecida em 1948, em Bogotá, na Colômbia, entrando em vigor somente no ano de 1951. Foi criada com a finalidade de implantar nos Estados membros "uma ordem de paz e de justiça" e congrega, atualmente, trinta e cinco estados independentes (OEA, 2020).

Tem como um dos seus primeiros documentos a Declaração Americana dos Direitos Humanos, aprovada na IX Conferência Internacional Americana, realizada na capital da Colômbia. Esta segue a diretriz dos documentos que existiam à época, proclamando uma série 
de direitos, mas distancia-se deles em um outro aspecto: enunciando também deveres (BARRETTO, 2012, p.160).

Além deste documento, existe no Sistema Interamericano, a Convenção Interamericana de Direitos Humanos, também conhecida como Pacto de São José da Costa Rica, que possui este "apelido" por ter sido celebrada na cidade de São José, na Costa Rica, em 22 de novembro de 1969, sendo o principal documento desta organização (BARRETTO, 2012, p.160).

Ratificado e promulgado pelo Brasil em 1992, este documento assegurou ao país o reconhecimento de um catálogo de direitos civis e políticos, que visava expandir, cada vez mais, sua visibilidade em território nacional (RAMOS, 2020, p.335).

Além disso, existe a previsão dos mecanismos de fiscalização, compostos pela Comissão Interamericana de Direitos Humanos e pela Corte Interamericana de Direitos Humanos, que, em síntese, possuem a incumbência de verificar e fiscalizar se os Estados permanecem cumprindo as diretrizes propostas pela Convenção (BARRETTO, 2012, p.161).

Sendo assim, alguns casos de violação ocorridos no Estado brasileiro já passaram pelo crivo da Comissão e também da Corte, tendo esta última aplicado, em alguns casos, medidas em desfavor dos violadores e do próprio ente federativo, como meio de resposta de não incentivo às práticas desabonadoras dos Direitos Humanos (BELTRAMELLI, 2014, p.366).

Dessa forma, diante de tais decisões, faz-se necessária uma reflexão acerca de seus cumprimentos por parte do Estado brasileiro, no que diz respeito às sentenças pecuniárias. Isso se dá, sobretudo, por não existirem muitos trabalhos a respeito do tema, Nesse contexto, excluem-se as sentenças que tratam de obrigação de fazer e não fazer, analisando-se, de fato, se as decisões que concernem condenações pecuniárias foram cumpridas e o modo pelo qual se procede esta execução. Trata-se, assim, de um apanhado geral sobre a forma de cumprimento, sem especificar, detalhadamente, cada um dos casos. Por tanto, pretende-se, com esta pesquisa, responder à seguinte indagação: Quando condenado o Brasil, de que forma se procede a execução pecuniária das sentenças proferidas pela Corte Interamericana de Direitos Humanos?

A partir do problema central, outras questões são abordadas, como a análise das medidas que o Poder Legislativo já realizou sobre o tema. Com isto, busca-se confirmar nesta pesquisa a observância dos efeitos da coisa julgada nos julgamentos pecuniários em que o Brasil ocupou 
o polo passivo da demanda. Ressalta-se ainda que, mesmo sem uma lei específica acerca do tema, o país cumpre as determinações, identificando como uma sentença proferida por um órgão não nacional é cumprida.

\section{A CORTE INTERAMERICANA DE DIREITOS HUMANOS}

A Corte Interamericana de Direitos Humanos é o órgão jurisdicional do sistema interamericano, previsto nos artigos 52 a 69 da Convenção, o qual desempenha um papel fundamental na Tutela Jurídica Internacional dos direitos humanos no âmbito americano. Representa, assim, uma nova alternativa para quem busca a reparação de direitos humanos violados pelos Estados (BARRETTO, 2012, p.176).

Trata-se de uma instância jurisdicional internacional prevista na Convenção Interamericana de Direitos Humanos, também conhecido como Pacto de São José da Costa Rica, sendo o principal documento deste sistema (BARRETTO, 2012, p.177).

No Brasil, este texto foi ratificado no dia 25 de setembro de 1992, sendo promulgado na ordem interna no dia 06 de novembro de 1992, pelo Decreto presidencial 678. A partir de então, assegurou-se e reconheceu-se um catálogo de direitos civis e políticos, como: o direito à personalidade jurídica, o direito à vida, o direito de não ser submetido à escravidão, o direito à liberdade, o direito a um julgamento justo, o direito à privacidade, o direito à liberdade de pensamento, dentre outros mais (RAMOS, 2020, p.443).

Nesse contexto, com a adesão do Brasil ao referido Pacto, vítimas de violação de direitos humanos que não tiveram seus casos solucionados satisfatoriamente no âmbito interno têm conseguido obter a tutela da Corte Interamericana, que, de fato, já condenou o Brasil a indenizar pessoas cujos direitos foram violados pelas autoridades brasileiras (RAMOS, 2020, p.444).

A existência da Corte, a atuação que ela vem tendo, no sentido de não deixar impunes os Estados que promovem violações de direitos humanos, representa algo muito relevante no processo de afirmação destes direitos (BARRETTO, 2012, p.179). 
Em outras palavras, a simples existência de um Tribunal que tem o condão de julgar casos relacionados a direitos humanos que a Justiça interna de determinados países, por alguma razão não julgaram, já perfaz uma evolução tamanha no que diz respeito a esta temática (BELTRAMELLI, 2014, p.367).

Esta Corte é composta por sete juízes nacionais de algum dos países membros da OEA (Organização dos estados Americanos), tendo a exigência de não poder existir dois juízes da mesma nacionalidade, sendo cada qual eleito em Assembleia geral da OEA, pelo voto da maioria absoluta dos Estados membros da Organização, devendo ser juristas de alta autoridade moral e reconhecida competência em matérias de direitos humanos (RAMOS, 2020, p.443).

Estes juízes possuem um mandato de seis anos, sendo admitida uma recondução e, como regra geral, os mesmos exercem suas funções até o fim do mandato. A única hipótese que pode prorrogar seu mandato é em caso de o processo se encontrar em fase de sentença, pois, aqui, o juiz que já instruiu o processo, permanecerá como julgador até o seu fim (RAMOS, 2020, p.443).

No que diz respeito à legitimidade, o art. 61 da Convenção estabelece que somente os Estados membros e a Comissão a possuem, no que diz respeito a levar um caso a julgamento pela Corte, não se atribuindo esta legitimidade a pessoas, grupos de pessoas ou entidades nãogovernamentais. Contudo, cabe mencionar que, em casos excepcionais, a Corte pode julgar casos vindos destes grupos (BARRETTO, 2012, p.179), situação esta que, por não ser o foco deste trabalho, não merece maior aprofundamento.

Segundo o artigo 64 da Convenção Interamericana, sua competência pode ser contenciosa ou consultiva, ou seja, a Corte pode examinar litígios submetidos à sua apreciação ou pode, simplesmente, responder a questionamentos a respeito da interpretação de alguma norma ou regulamentação do Sistema Interamericano de Direitos Humanos, ou até mesmo acerca da compatibilidade de normas internas de cada Estado com a Convenção Interamericana de Direitos Humanos (BARRETTO, 2012, p.181).

Além disso, ainda no que diz respeito à competência, a Corte tem natureza facultativa, ou seja, só pode atuar em relação a Estados que reconheçam sua competência como obrigatória para os casos envolvendo o Sistema Americano (BARRETTO, 2012, p.181), isto quer dizer 
que nenhum Estado possui cláusula obrigatória para exame de jurisdição contenciosa na Corte, sendo todos, como já ressaltado, de natureza facultativa.

O Brasil declarou o seu reconhecimento da competência da Corte em 10 de dezembro de 1998, tendo a declaração sido promulgada na ordem interna pelo Decreto Presidencial 4463, de 4 de novembro de 2002. Aqui, cumpre ressaltar que o Brasil reconheceu a competência da Corte por prazo indeterminado e para todos os casos envolvendo a interpretação e a aplicação da Convenção, mas sob reserva de reciprocidade e apenas para fatos posteriores a 10 de dezembro de 1998 (BARRETTO, 2012, p.181).

Com isso, não custa frisar que, como se observa acima, a data de reconhecimento da competência da Corte Interamericana de Direitos Humanos foi diversa da que o Brasil ratificou o Pacto de São José da Costa Rica (BARRETTO, 2012, p.181).

Assim, passadas as considerações iniciais acerca da temática de cumprimento das sentenças proferidas pela Corte Interamericana de Direitos Humanos, entra-se especificamente na questão do cumprimento no âmbito interno das sentenças prolatadas pela Corte Interamericana.

\section{CUMPRIMENTO DAS SENTENÇAS DA CORTE INTERAMERICANA DE DIREITOS HUMANOS}

Publicada a sentença proferida pela Corte Interamericana, resta saber como se procede sua execução e de que forma o Brasil cumpre com as ordens judiciais que a mesma prescreve.

A última etapa do procedimento contencioso no Sistema Interamericano de Direitos Humanos é composta pelo cumprimento dessas reparações, ou seja, é a fase de supervisão de cumprimento de sentença, que vem se tornando uma das atividades que concentra a maior ocupação da Corte, uma vez que a complexidade dos conflitos exige que cada reparação seja supervisionada de maneira pormenorizada (NEVES; PACHECO; FERREIRA, 2017, p.306). 
Somado a isto, até 2017, das seis sentenças que reconheceram a responsabilização internacional do Brasil por violação de direitos humanos, somente uma foi considerada totalmente cumprida, possuindo o restante o status de cumprimento parcial (NEVES; PACHECO; FERREIRA, 2017, p.306).

As convenções internacionais instituem um órgão executivo, que possui a competência para atuar em relação aos mecanismos fiscalizatórios instituídos (BARRETTO, 2012, p.170).

Estes mecanismos são os relatórios, comunicações interestatais e petições individuais que, dentre outras funções, servem para monitorar as violações de direitos humanos de cada localidade subscrita ao Sistema Interamericano, tendo cada uma sua respectiva função, visando a difusão das normas (BARRETTO, 2012, p.170).

Os relatórios consistem na obrigação imposta aos Estados de submeter, periodicamente, e sempre que solicitado pelo órgão executivo, documentos que informem acerca das medidas adotadas quanto ao cumprimento das obrigações assumidas em virtude da Convenção. Os mesmos encontram-se previstos em todas as convenções internacionais e é obrigatório a todas as nações partes. Cada Convenção define o seu conteúdo, a periodicidade e o seu destino. Além do mais, os comitês têm a prerrogativa de solicitar informes aos Estados membros sempre que considerar necessário (BELTRAMELLI, 2014, p.257).

As comunicações interestatais são os relatos feitos por um estado em função do outro, acerca das obrigações assumidas em razão da Convenção. Aqui, um Estado membro afirma ao órgão executivo que outro Estado membro encontra-se violando obrigações assumidas previamente. Assim, o Estado que recebe a denúncia deve encaminhar explicações e esclarecimentos sobre a comunicação e, não sendo dirimida a questão, o órgão executivo pode intervir. Tal situação se fundamenta na ideia da actio popularis, segundo a qual a proteção dos direitos humanos é de interesse de toda e qualquer nação (BARRETTO, 2012, p.173).

Trata-se de mecanismo de natureza facultativa, significando dizer que o órgão executivo somente poderá agir se os Estados envolvidos tiverem declarado que reconhecem a competência do órgão. Caso um Estado não reconheça, o órgão nada poderá fazer a respeito (BARRETTO, 2012, p.173). 
Além destes dois mecanismos, existem as petições individuais, que representam uma evolução no sistema de fiscalização, sendo consideradas o mecanismo mais eficiente, já que permite que pessoas ou grupo de pessoas denunciem o descumprimento das Convenções, consistindo em petições feitas por pessoas ao órgão executivo sob a alegação de estarem sendo vítimas de violação em seus direitos (BARRETTO, 2012, p.174).

A Convenção Americana conta apenas com um artigo que dispõe acerca do cumprimento das sentenças prolatada pela Corte Interamericana. O art. 68 da Convenção, em seu parágrafo primeiro, expõe que os Estados partes na Convenção comprometem-se a cumprir a decisão da Corte em todo caso que forem partes, ou seja, a norma deixa claro que as sentenças proferidas pela Corte vinculam os Estados que foram partes no processo. Percebe-se que a Convenção não prevê um procedimento específico para este cumprimento. A execução dessas sentenças se dá conforme a normatividade interna, cabendo, portanto, a cada Estado decidir como se executam os comandos da Corte, segundo seu ordenamento jurídico interno (RAMOS, 2020, p.450).

Ainda sobre este artigo, seu parágrafo segundo reza que a parte da sentença que determinar indenização compensatória pode ser executada no país respectivo pelo processo interno vigente para a execução de sentenças contra o Estado. Assim, em outras palavras, isto possibilita que o Estado utilize regras do seu direito interno, previstas para a execução de sentenças contra o Estado, para executar a parte indenizatória das sentenças da Corte (RAMOS, 2020, p.451).

Então, no que diz respeito às indenizações pecuniárias, as sentenças da Corte são autoexecutáveis, pois é apenas necessário que se utilize o procedimento já existente contra a Fazenda Pública (CASTAÑEDA, 2013).

Neste sentido, pode-se dizer que o art. 68.2 significa um importante avanço no que tange à reparação direta às vítimas de violações de direitos humanos, uma vez que garante a plena executividade, no âmbito interno, das indenizações compensatórias fixadas nas sentenças internacionais (RAMOS, 2020, p.494). 
Com isso, o que se observa é que não existe um procedimento específico para executar as indenizações pecuniárias impostas pela Corte, podendo ser utilizado o procedimento interno já existente para execução de sentenças contra o Estado.

Mas, e o Brasil? Como se dá este cumprimento no âmbito jurídico interno brasileiro?

Inicialmente, é necessário diferenciar as sentenças internacionais das sentenças estrangeiras.

Sentença estrangeira é aquela decisão proferida por um Estado para ser executada em outro, devendo, assim, ser recebida por um ato oficial do país destinatário, no qual se procede a homologação e se dá eficácia à decisão (MAGALHÃES, 1999, p.287).

Já a sentença internacional não é proferida por um Estado, mas sim por um Tribunal internacional de que o país destinatário faça parte. É proveniente de um tribunal ao qual o Estado deve aceitar se submeter à jurisdição do tribunal para ser processado e julgado. Neste sentido, é exatamente isto que ocorre nas decisões da Corte Interamericana (MAGALHÃES, 1999, p.287).

Além do mais, nota-se que as sentenças internacionais não necessitam de homologação por parte do Superior Tribunal de Justiça, ao passo que as estrangeiras necessitam para surtir efeitos no território brasileiro. Esta homologação se justifica pelo fato de que o Brasil ratificou (REZEK, 2011, p.52), previamente, a Convenção Americana de Direitos Humanos, por meio da qual aceitou se submeter à jurisdição da Corte Interamericana de Direitos Humanos. Assim, as sentenças proferidas por este tribunal internacional (classificadas como sentenças internacionais) produzem plenos efeitos no âmbito interno do Estado brasileiro, sendo desnecessário qualquer procedimento para lhes conferir efetividade (RAMOS, 2020, p.495).

Com isso, foi introduzido no ordenamento jurídico brasileiro uma nova espécie de sentença, a sentença internacional proferida pela Corte Interamericana, como uma nova hipótese de execução judicial contra o Estado embasada no título judicial oriundo de sentença internacional (RAMOS, 2020, p.495).

Analisando a legislação interna, observa-se, no Código de Processo Civil, mais especificamente no art. 475-N, VI, que apenas a sentença estrangeira encontra-se prevista no 
rol dos títulos executivos judiciais, sendo que sua execução se dá de acordo com o art. 484, do mesmo código, o qual dispõe que essa se faz mediante carta de sentença extraída dos autos da homologação e deve obedecer às regras estabelecidas para a execução da sentença nacional da mesma natureza (BRASIL, 2015).

Com isso, quando a Corte fixa uma indenização compensatória à vítima, a sentença vale como título executivo a ser executado contra o Estado, mesmo não estando as sentenças internacionais incluídas no rol do art. 475-N, do CPC. Assim, até mesmo pelo que já fora exposto acerca do art. 68 da Convenção, destaca-se que o fato de não existir um procedimento específico para a execução da sentença da Corte não significa que o Brasil possa descumpri-la (NEVES; PACHECO; FERREIRA, 2017, p.319).

Assim, as sentenças da Corte que impõem ao Estado brasileiro a obrigação de indenizar as vítimas de violações de Direitos Humanos vêm sendo cumpridas por meio de decreto autônomo, fundamentando-se no artigo 84, IV, da Constituição Federal, podendo citar como exemplo: o Decreto $\mathrm{n}^{\circ}$ 6.185, de 13 de agosto de 2007 - Caso Damião Ximenes Lopes; Decreto n 7.158 de 20 de abril de 2010 - Caso Arley José Escher e outros; Decreto no 7.307 de 22 de setembro de 2010 - Caso Sétimo Garibaldi (NEVES; PACHECO; FERREIRA, 2017, p.319).

Desta forma, o Brasil poderia utilizar a sistemática dos precatórios, de acordo com o artigo 68.2 da Convenção, que é o procedimento existente para executar sentenças contra o Estado, valendo ressaltar que esta forma seria legalmente adequada, ainda que não a mais eficaz (LEITE, 2015).

Ocorre que toda a mora envolvida no pagamento dos precatórios prejudicaria ainda mais as vítimas, em razão da ineficiência e demora do sistema e, além disso, poderia prejudicar toda a nação, já que o nome do país seria incluído na lista de países que não cumpriram com a sentença da Corte. Portanto, corrobora-se a necessidade de um procedimento específico para pagamento das condenações pecuniárias (LEITE, 2015).

Desta forma, não existem, no Brasil, mecanismos legais próprios para executar as sentenças da Corte, sendo que o único instituto legal para executar uma quantia certa, até o presente momento, é por meio de título executivo judicial, no momento que se tem uma 
sentença transitada em julgado, seguindo-se exatamente a doutrina dos artigos 730 e 731, do CPC (LEITE, 2015).

A execução contra a Fazenda Pública obedece a esses dispositivos e, sobretudo, ao artigo 100 da Constituição Federal, o qual prevê a ordem para pagamento das dívidas das Fazendas Públicas Federal, Estaduais, Distrital e Municipais (BRASIL, 2015).

$\mathrm{O}$ art. $84, \mathrm{IV}, \mathrm{CF} / 88$ ressalta cerca da execução por meio de decreto presidencial, cumprindo, assim, com o requisito da rápida e efetiva reparação à vítima, uma vez que não precisa da tramitação prevista para a execução por meio de precatórios (LEITE, 2015).

Assim, o instituto se mostrou correto nos dois casos em que foram expedidos tais decretos para o pagamento de indenização à vítima, pois as leis orçamentárias continham autorização para abertura de crédito suplementar, relativos às despesas da União, para fins de despesas oriundas de sentenças judiciais transitadas em julgado (LEITE, 2015).

Com isso, as sentenças proferidas pela Corte têm plena efetividade no Estado brasileiro, já que aderiram previamente à Convenção (LEITE, 2015).

A lei que previa e fixava as despesas da União, Decreto $n^{\circ} 6185 / 2007$, serviu como parâmetro no caso Damião Ximenes Lopes, pois continha no seu art. $4^{\circ}$, III, a autorização para abertura de crédito suplementar para tal fim. Da mesma forma, no caso Arley José Escher e outros, a autorização para abertura do crédito suplementar para despesas decorrentes de sentenças judiciais estava prevista na Lei $\mathrm{n}^{\circ} 12.214 / 07$ e foi executado por meio do Decreto $\mathrm{n}^{\circ}$ 7.158, de 20 de abril de 2010. Portanto, nestes casos, havia previsão orçamentária estabelecida em lei, o que autorizava a expedição dos decretos (NEVES; PACHECO; FERREIRA, 2017, p.319).

Então, atualmente, o Estado, tem duas opções para executar a sentença de cunho pecuniário da Corte: espontaneamente, como ocorreu no caso Damião Ximenes Lopes, por meio do Poder Executivo, em que a condenação foi satisfeita pelo Decreto $n^{\circ}$. 6.185/2007, ou ainda pode se executar tendo como base do Código de Processo Civil, pagando-se pelo sistema de precatório, conforme expõe o artigo 68 da Convenção (LEITE, 2015). 
Com isso, analisando-se alguns projetos de lei, nota-se a intenção do Congresso Nacional em regulamentar a matéria, observando-se que, até o momento, nenhum projeto virou lei. Contudo, é inquestionável a intenção em normatizar o assunto, bastando informar que a primeira PL data do ano 2000 e foi de autoria do Deputado Federal Marcos Rolim e rezava que todas as decisões provenientes da Corte ou da Comissão teriam efeito jurídico imediato no ordenamento brasileiro (BRASIL, 2000).

No ano de 2004, mais uma tentativa foi feita, desta vez pelo Deputado José Eduardo Cardozo. Aqui, o projeto não foi finalizado, pois acreditava-se que, na tramitação do Novo Código de Processo Civil, esta temática seria abrangida, restando, assim, o PL prejudicado (LEITE, 2015).

Ocorre que o novo CPC não abrangeu o assunto e o projeto terminou sendo arquivado, perdendo, assim, mais uma oportunidade em se dar mais eficácia aos Direitos Humanos (LEITE, 2015).

\section{CONSIDERAÇÕES FINAIS}

Cada vez mais se observa no Brasil o incremento de práticas de celeridade, pois adotase a agilidade de incluir na lei anual que estima a receita e prevê as despesas da União, com o fim de emitir créditos suplementares para quitação de sentenças judiciais.

Em razão disso, o chefe do Executivo estaria autorizado a promulgar um decreto para a fiel execução desta lei. Ocorre que, mesmo que este meio tenha a devida celeridade, ele não gera a segurança e estabilidade necessária à vítima, pois a expedição do decreto encontra-se ao bel-prazer do Poder Executivo. Em outras palavras, o cumprimento de uma decisão judicial estaria ao dispor de uma única pessoa, o que poderia gerar uma insegurança sem precedentes.

Além disto, a execução através do procedimento explicitado no Código de Processo Civil, também presente em nossa Constituição Federal (art. 100), não seria o caminho mais adequado para cumprimento das condenações da Corte por duas razões: a morosidade deste 
sistema, pois permitiria a satisfação da obrigação somente após anos, ou até mesmo décadas depois de julgado.

Além de tudo, mesmo que se equiparassem os direitos humanos ao procedimento de precatórios alimentícios, que possui um trâmite mais célere, ainda assim, seria deveras moroso, uma vez que a quantidade de pessoas que se encontram na fila aguardando receber indenizações da mesma natureza é muito elevada. Assim, submeter uma condenação pecuniária da Corte seria equiparar os direitos humanos a qualquer outra forma de condenação, retirando, assim, o caráter especial daqueles direitos. Desse modo, não parece injusto conceder uma maior celeridade às execuções das sentenças internacionais.

À primeira vista, pode parecer não razoável permitir que as execuções da CIDH sejam menos morosas que as nacionais. Ocorre que, deve-se analisar que uma decisão internacional naturalmente já tramitou por todas as instâncias internas (necessidade de esgotamento dos recursos internos para acessar o Sistema Interamericano) e, além disso, ainda teve que enfrentar todas as barreiras que o acesso à Corte já encontra, seja pela legitimidade restrita ou até pela impossibilidade de uma pessoa ou grupo de pessoas conseguir levar um caso ao tribunal em questão.

Além disso, autores renomados ressaltam que a sentença condenatória da Corte Interamericana, no tocante a valores pecuniários, poderá ser executada perante a Vara Federal territorialmente competente, sendo descartada a necessidade de homologação da sentença da Corte, uma vez que não se trata de sentença estrangeira (NEVES; PACHECO; FERREIRA, 2017, p.320).

Por isto, é nítida a sinalização da casa legislativa nacional a fim de positivar este modo de cumprimento de decisões especiais, restando informar que retirar esta nebulosidade na execução de sentenças da Corte Interamericana seria atitude extremamente bem-vinda ao país e àqueles que têm ou terão algum tipo de violação desta modalidade de direito. 


\section{REFERÊNCIAS BIBLIOGRÁFICAS}

BARRETO, Rafael. Direitos Humanos. Salvador: JusPodivm, 2012.

BRASIL. Câmara dos Deputados. Projeto de Lei 3214/2000. Dispõe sobre os efeitos jurídicos das decisões da Comissão Interamericana de Direitos Humanos e da Corte Interamericana de Direitos Humanos e dá outras providências. Disponível em: https://www.camara.leg.br/proposicoesWeb/fichadetramitacao?idProposicao=19288. Acesso em: 08 jun. 2020.

BRASIL. Constituição Federal de 1988. Disponível em: http://www.planalto.gov.br/ccivil_03/constituicao/constituicao.htm. Acesso em: 22 dez. 2019.

BRASIL. Decreto no 678, de 6 de novembro de 1992, que "Promulga a Convenção Americana sobre Direitos Humanos (Pacto de São José da Costa Rica), de 22 de novembro de 1969”. DOU de 9.11.1992. BRASIL, 1992.

BRASIL. Lei $\mathbf{n}^{\circ}$ 13.105, de 16 de março de 2015. Disponível em: http://www.planalto.gov.br/ccivil_03/leis/113105.htm. Acesso em: 22 jun. 2019.

CASTAÑEDA, Juan Antonio Rosas. Ejecución de la sentencias de la Corte Interamericana de Derechos Humanos: Caso del Peru y la Reforma Constitucional. Disponível em: http://www.oocities.org/es/tadi_unmsm/ejecucion_sentencias_cidh.pdf. Acesso em: 22 dez. 2019.

CRUZ, Paulo Márcio; BODNAR, Zenildo. O novo paradigma de Direito na pós-modernidade. Porto Alegre - RECHT/UNISINOS. Revista de estudos Constitucionais, Hermenêutica e Teoria do Direito, v. 3, 2011

JESSUP, Philip C. Direito Transnacional. Trad. Carlos Ramires Pinheiro da Silva. São Paulo: Fundo de Cultura, 1965.

KIBRIT, Orly. Atuação Cotenciosa da Corte Interamericana de Direitos Humanos no contexto brasileiro. São Paulo: Lumen Juris, 2018.

KOH, Harold Hongju. Transnational Legal Process. Nebraska: Yale law Journal, 1996.

LEITE, Rodrigo de Almeida. As sentenças da Corte Interamericana de Direitos Humanos e a execução no Brasil. http://www.esmarn.tjrn.jus.br/revistas/index.php/revista_direito_e_liberdade/article/viewFile/ 34/26. Acesso em: 22 dez. 2019.

MAGALHÃES, José Carlos. O protocolo de Las Leñas e a eficácia extraterritorial das sentenças e laudos arbitrais nos países do MERCOSUL. Revista de Informação Legislativa. Brasília, a. 36, n.144, p.287, out./dez., 1999. 
MAZZUOLI, Valerio de Oliveira. Curso de Direito Internacional Público. 5. ed. São Paulo: Editora Revista dos Tribunais, 2010.

NETO, Silvio Beltramelli. Direitos Humanos. Salvador: JusPodivm, 2014.

NEVES, R.; PACHECO, A.; FERREIRA, V. Como os Estados cumprem suas sentenças internacionais? As medidas de adequação institucional cridas pelo Brasil e México para dar cumprimento às da CorteIDH. Rio de janeiro: Lumen Juris, 2017.

OEA. Organização dos Estados Americanos. Quem somos. Disponível em http://www.oas.org/pt/sobre/quem_somos.asp. Acesso em: 26 de ago. 2020.

OLIVIERO, Maurizio; CRUZ, Paulo Márcio. Reflexões sobre o direito transnacional. Revista Novos Estudos Jurídicos. Itajaí, v. 17, n. 1, p. 18-28, 2012.

OLIVIERO, Maurizio. Reflexões sobre o Direito Transnacional. São Paulo: Editora Novos Estudos Jurídicos, 2010.

PETERKE, Sven.(Coord.) et al (Col.). Manual prático de direitos humanos internacionais. Brasília: Escola Superior do Ministério Público da União, 2009.

PIOVESAN, Flavia. Direitos Humanos e o Direito Constitucional Internacional. São Paulo: Saraiva, 2012.

RAMOS, André de Carvalho. Processo Internacional dos Direitos Humanos. São Paulo: Saraiva, 2019.

REZENDE, Marcelo Di. As Decisões da Corte Interamericana de Direitos Humanos no Brasil. São Paulo: Novas Edições Acadêmicas, 2015.

SIEYÈS, Emmanuel Joseph. A constituinte burguesa (Qu'est-ce que le tiers état?). Trad. Norma Azevedo. Rio de Janeiro: Liber Juris, 1986.

Data de Submissão: 13/11/2020

Data de Aceite: 16/03/2021 